\title{
GAMBARAN SISA MAKANAN BIASA YANG DISAJIKAN DIBERI GARNIS DAN TIDAK DIBERI GARNIS DIRUANG VIP RSUD UNDATA PROVINSI SULAWESI TENGAH
}

\section{Description Of Ordinary Left Over Served With Garnished And Ungarnished In VIP Room Of Undata Hospital Of Central Sulawesi}

\author{
Putu Candriasih ${ }^{1)}$, Hermin Austeria ${ }^{2)}$ Made Ayu Puspitawati ${ }^{3)^{*}}$, \\ ${ }^{1,3}$ Poltekkes Kemenkes Palu \\ ${ }^{2}$ RSUD Undata Palu \\ (madeayu022@gmail.com, 0812-4501-7221)
}

\begin{abstract}
ABSTRAK
Penyelenggaraan makanan merupakan salah satu bentuk pelayan gizi di rumah sakit. Penyelengaraan makanan dilakukan untuk menyediakan makanan dengan kualitas yang baik, jumlah yang sesuai dengan kebutuhan serta pelayanan yang memadai bagi pasien. Kepuasaan pasien terhadap tampilan dan rasa makanan dapat merangsang selera makan. Tampilan makanan yang kurang baik dan menarik akan menyebabkan banyaknya sisa makanan pasien. Tujuan penelitian ini adalah untuk mengetahui gambaran sisa makanan biasa yang disajikan dengan diberi garnis dan tidak diberi garnis di ruang VIP RSUD Undata Palu Provinsi Sulawesi Tengah. Penelitian ini adalah penelitian deskriptif. Populasi penelitian ini adalah seluruh pasien yang dirawat di ruang VIP RSUD Undata Palu. Sampel dalam penelitian ini berjumlah 12 responden yang terdiri dari 6 responden diruang Anggrek (tidak diberi garnis) dan 6 responden diruang Edelweis (diberi garnis). Hasil penelitian menunjukan bahwa seluruh responden (100\%) yang makanannya ditambahkan garnis menghabiskan seluruh makanan tanpa sisa, sedangkan responden yang diberikan makanan tanpa menambahkan garnis hanya 1 responden $(16,6 \%)$ yang menghabiskan makanan. Penambahan garnis disarankan agar dapat mengurangi sisa makanan pasien dirumah sakit.
\end{abstract}

Kata Kunci : Sisa makanan, garnish, tanpa garnish

\section{ABSTRACT}

Food service is one form of nutrition service in hospitals. Food management is carried out to provide food of good quality, quantity according to the needs and adequate service for patients. Patient satisfaction with the appearance and taste of food can stimulate appetite. The appearance of food that is not good and attractive will cause a lot of patient food waste. The purpose of this study was to determine the description of the usual leftovers served with garnished and ungarnished in the VIP room of Undata Hospital Palu, Central Sulawesi Province. This research is descriptive research. The population of this study were all patients who were treated in the VIP room of the Undata Hospital Palu. The sample in this study amounted to 12 respondents consisting of 6 respondents in the Orchid room (not given a garnish) and 6 respondents in the Edelweiss room (garnished). The results showed that all respondents (100\%) whose food was added with garnish spent all the food without leftovers, while respondents who were given food without adding garnish only 1 respondent $(16.6 \%)$ finished the food. The addition of garnish is recommended in order to reduce the patient's food waste in the hospital.

Keywords : Leftovers, garnish, without garnish 


\section{PENDAHULUAN}

Rumah sakit merupakan salah satu industri jasa kesehatan yang semula hanya melaksanakan kegiatan penyembuhan dan pemulihan saja (Sibagariang, 2018). Akan tetapi dengan adanya perkembangan ilmu pengetahuan dan teknologi, rumah sakit juga melaksanakan upaya peningkatan kualitas pelayanan. Proses penyembuhan pasien dapat dibantu dengan adanya makanan yang memenuhi syarat, makanan yang dikatakan memenuhi syarat tentunya melalui proses penyelenggaraan makanan, guna untuk pencapaian status kesehatan terutama gizi yang optimal (Yulianti \& Damanik, 2015). Keadaan gizi pasien sangat berpengaruh pada proses penyembuhan penyakit, sebaliknya proses perjalanan penyakit dapat berpengaruh terhadap keadaan gizi pasien. Sering terjadi kondisi pasien yang semakin buruk karena tidak tercukupinya kebutuhan zat gizi untuk perbaikan organ tubuh. Pelayanan yang dilakukan oleh ahli gizi salah satunya adalah penyelenggaraan makanan, pada penyelenggaraan makanan seorang ahli gizi harus memperhatikan menu makanan pasien agar sesuai dengan masalah yang dialami oleh pasien. Terkadang pelayanan dari rumah sakit kurang memberikan kepuasan kepada pasien, hal ini juga dapat memberi efek terhadap pasien sehingga beranggapan buruk terhadap pelayanan kesehatan terutama tentang makanan dari rumah sakit sendiri (Mustakim, Kusuma, \& Ulvie, 2012). Hal inilah yang menjadi penyebab kualitas makanan rumah sakit perlu diperhatikan. Masalah penyajian makanan untuk orang sakit lebih kompleks dari pada penyajian makanan untuk orang sehat. Sehingga, nafsu makan serta kondisi mental orang sakit berubah dan menurun akibat penyakit yang dideritanya. Nafsu makan bisa dipulihkan kembali dengan memberikan makanan yang memiliki cita rasa, variasi menu, dan penampilan yang menarik. Kepuasan pasien dalam penampilan dan rasa makanan sangat berkaitan dengan sisa makanan pasien, dimana penyajian makanan yang kurang baik dapat berdampak pada banyaknya sisa makanan pasien (Habiba \& Adriani, 2017). Penampilan makanan dapat diamati dari warna, tekstur, aroma, dan rasa. Tampilan hidangan yang berhubungan langsung dengan indera penglihatan yang memberikan penilaian pertama dari sebuah hidangan, sehingga melahirkan rangsangan untuk menikmati makanan tersebut atau dengan kata lain, dapat merangsang selera makan pasien (Gobel \& Budiningsari, 2011).

Penelitian yang dilakukan oleh Wirasamadi, dkk (2015) menyatakan bahwa beberapa rumah sakit (RS) di Indonesia ratarata sisa makanan sangat bervariasi antara 17\%-67\% (L, K, \& W, 2015). Penelitian yang dilakukan di RS Hasan Sadikin kota Bandung tahun 2015 didapatkan sisa makan pagi sebesar 31,2\% sedangkan, di RS Dr. Sardjito Yogyakarta dijumpai rata-rata sisa makan pagi sebesar 23,41\%. Berdasarkan Kepmenkes No.129/Menkes/SK/II/2008 tentang Standar Pelayanan Minimal Rumah Sakit (SPM), sisa makanan yang tidak termakan oleh pasien sebanyak-banyaknya $20 \%$. Terpenuhinya 
syarat tersebut menjadi indikator keberhasilan pelayanan gizi di setiap rumah sakit di Indonesia.

Penelitian ini bertujuan untuk mengetahui gambaran sisa makanan biasa yang disajikan dengan diberi garnis dan tidak diberi garnis di ruang VIP RSUD Undata Palu Provinsi Sulawesi Tengah.

\section{METODE PENELITIAN}

Penelitian ini merupakan penelitian deskriptif. Penelitian ini dilaksanakan pada 12 Februari-12 Maret 2020 yang berlokasi di RSUD Undata Palu Provinsi Sulawesi Tengah. Populasi pada penelitian ini adalah seluruh pasien yang mendapatkan makanan biasa di ruang VIP Anggrek dan Edelweis RSUD Undata Palu. Sampel berjumlah 12 responden yang terdiri dari 6 responden di ruang Anggrek dan 6 orang di ruang Edelweis. Ruang angrrek diberikan makanan tanpa menambahkan garnish dan diruang Edelweis diberikan garnish. Pemilihan sampel berdasarkan kriteria inklusi yang telah ditetapkan diantaranya yaitu (1) Pasien dewasa yang dirawat di ruang VIP Anggrek atau Edelweis, (2) pasien yang bersedia menjadi responden, (3) pasien yang dalam keadaan sadar, (4) pasien yang bisa berkomunikasi dengan baik, dan (5) pasien yang mendapat bentuk makanan biasa.

Penelitian ini hanya melibatkan 1 orang saja, yang telah mengetahui standar porsi Rumah Sakit Undata dan untuk mengukur sisa makanan secara visual dengan menggunakan skala Comstock dengan 6 kriteria yang selanjutnya dinilai reliabilitasnya (Puruhita,
Hagnyonowati, Adianto, Murbawani, \& Ardiaria, 2014). Sedangkan, untuk penampilan diukur dengan kuesioner dimana pasien diwawancarai. Sisa makanan dikategorikan bersisa jika sisa makan banyak (>25\%) dan tidak bersisa jika sisa makanan sedikit $(\leq 25 \%)$

\section{HASIL}

Penelitian ini dilakukan pada pasien Ruang VIP Edelweis dan Anggrek RSUD Undata Palu pada 12 Februari - Maret 2020. Dengan sampel sebanyak 12 orang yang terdiri dari 6 orang dari ruang Anggrek dan 6 orang dari ruangan Edelweis.

Karakterisitik subjek penelitian ini berdasarkan :

Tabel 1. Distribusi Jumlah Pasien Berdasarkan Jenis Kelamin

\begin{tabular}{ccc}
\hline Jenis Kelamin & n & \% \\
\hline Laki-Laki & 3 & 25 \\
Perempuan & 9 & 75 \\
\hline Total & 12 & $100 \%$
\end{tabular}

(Sumber : Data Primer, 2020)

Tabel diatas menunjukkan subjek penelitian berdasarkan jenis kelamin didapatkan jumlah sampel terbanyak adalah perempuan (Tabel 1).

Tabel 2. Distribusi Jumlah Pasien Berdasarkan Usia

\begin{tabular}{ccc}
\hline Usia (Tahun) & $\mathbf{n}$ & $\mathbf{\%}$ \\
\hline $20-30$ & 2 & 16,6 \\
$31-40$ & 4 & 33,2 \\
$41-50$ & 4 & 33,3 \\
$51-60$ & 2 & 16,7 \\
\hline Total & 12 & $100 \%$ \\
\hline
\end{tabular}

(Sumber : Data Primer, 2020)

Tabel diatas menunjukkan subjek penelitian berdasarkan usia didapatkan jumlah 
sampel terbanyak adalah usia 31-40 tahun dan

Tabel 3. Distribusi Jumlah Pasien Berdasarkan Pekerjaan

\begin{tabular}{lcc}
\hline Status Pekerjaan & $\mathrm{n}$ & $\%$ \\
\hline Bekerja & 7 & 58,3 \\
TidakBekerja & 5 & 41,7 \\
\hline Total & 12 & $100 \%$
\end{tabular}

(Sumber : Data Primer, 2020)

Tabel diatas menunjukkan bahwa responden dengan status pekerjaan bekerja lebih banyak dari pada responden yang tidak bekerja (Tabel 3). usia

$$
41-50
$$

tahun

(Tabel

2).

Tabel 4. Distribusi Jumlah Pasien Berdasarkan Pendidikan

\begin{tabular}{ccc}
\hline Pendidikan & $\mathrm{n}$ & $\%$ \\
\hline Tamat SLTA/SMA/sederajat & 4 & 33,3 \\
Perguruan Tinggi (DI-III/S1) & 8 & 66,7 \\
\hline Total & 12 & $100 \%$ \\
\hline
\end{tabular}

(Sumber : Data Primer, 2020)

Tabel diatas menunjukkan bahwa responden yang mendominasi adalah responden yang lulusan perguruan tinggi yaitu sebesar 66,7\% (Tabel 4).

Tabel 5. Distribusi Sisa Makanan Pasien Ruang Edelweis (Disajikan dengan diberi Garnis)

\begin{tabular}{|c|c|c|c|c|c|c|c|c|c|c|}
\hline \multirow{2}{*}{$\begin{array}{c}\% \text { Sisa } \\
\text { Makanan }\end{array}$} & \multicolumn{2}{|c|}{$\begin{array}{l}\text { Makan } \\
\text { Pokok }\end{array}$} & \multicolumn{2}{|c|}{$\begin{array}{c}\text { Lauk } \\
\text { Hewani }\end{array}$} & \multicolumn{2}{|c|}{$\begin{array}{l}\text { Lauk } \\
\text { Nabati }\end{array}$} & \multicolumn{2}{|c|}{ Sayur } & \multicolumn{2}{|c|}{ Buah } \\
\hline & $\mathrm{n}$ & $\%$ & $\mathrm{n}$ & $\%$ & $\mathrm{n}$ & $\%$ & $\mathrm{n}$ & $\%$ & $\mathrm{n}$ & $\%$ \\
\hline $0 \%$ & 0 & 0 & 0 & 0 & 2 & 33,33 & 1 & 16,66 & 6 & 100 \\
\hline $25 \%$ & 4 & 66,66 & 5 & 83,33 & 3 & 50,0 & 5 & 83,33 & 0 & 0 \\
\hline $50 \%$ & 2 & 33,33 & 1 & 16,66 & 1 & 16,66 & 0 & 0 & 0 & 0 \\
\hline $75 \%$ & 0 & 0 & 0 & 0 & 0 & 0 & 0 & 0 & 0 & 0 \\
\hline $95 \%$ & 0 & 0 & 0 & 0 & 0 & 0 & 0 & 0 & 0 & 0 \\
\hline $100 \%$ & 0 & 0 & 0 & 0 & 0 & 0 & 0 & 0 & 0 & 0 \\
\hline Total & 6 & 100 & 6 & 100 & 6 & 100 & 6 & 100 & 6 & 100 \\
\hline
\end{tabular}

(Sumber : Data Primer, 2020)

Tabel diatas menunjukkan bahwa untuk semua jenis makanan yang diberi garnish tidak ada sisa makanan yang $>50 \%$ (Tabel 5). Sedangkan makanan yang disajikan tanpa diberi garnis terdapat responden yang sisa makanannya $\geq 25 \%$, bahkan ada reponden yang tidak mengkonsumsi sama sekali makanannya (sisa makanan 100\%) (Tabel 6).

Tabel 6. Distribusi Sisa Makanan Pasien Ruang Anggrek (Disajikan Tanpa diberi Garnis)

\begin{tabular}{|c|c|c|c|c|c|c|c|c|c|c|}
\hline \multirow{2}{*}{$\begin{array}{c}\% \text { Sisa } \\
\text { Makanan }\end{array}$} & \multicolumn{2}{|c|}{$\begin{array}{l}\text { Makan } \\
\text { Pokok }\end{array}$} & \multicolumn{2}{|c|}{$\begin{array}{c}\text { Lauk } \\
\text { Hewani }\end{array}$} & \multicolumn{2}{|c|}{$\begin{array}{c}\text { Lauk } \\
\text { Nabati }\end{array}$} & \multicolumn{2}{|c|}{ Sayur } & \multicolumn{2}{|c|}{ Buah } \\
\hline & $\mathrm{n}$ & $\%$ & $\mathrm{n}$ & $\%$ & $\mathrm{n}$ & $\%$ & $\mathrm{n}$ & $\%$ & $\mathrm{n}$ & $\%$ \\
\hline $0 \%$ & 0 & 0 & 0 & 0 & 3 & 50 & 0 & 0 & 6 & 100 \\
\hline $25 \%$ & 1 & 16,66 & 2 & 33,33 & 1 & 16,66 & 0 & 0 & 0 & 0 \\
\hline $50 \%$ & 4 & 66,66 & 2 & 33,33 & 2 & 33,33 & 3 & 50,0 & 0 & 0 \\
\hline $75 \%$ & 1 & 16,66 & 1 & 16,66 & 0 & 0 & 2 & 33,33 & 0 & 0 \\
\hline $95 \%$ & 0 & 0 & 1 & 16,66 & 0 & 0 & 0 & 0 & 0 & 0 \\
\hline $100 \%$ & 0 & 0 & 0 & 0 & 0 & 0 & 1 & 16,66 & 0 & 0 \\
\hline Total & 6 & 100 & 6 & 100 & 6 & 100 & 6 & 100 & 6 & 100 \\
\hline
\end{tabular}

(Sumber : Data Primer, 2020)

Apabila dikategorikan berdasarkan status sisa makanan maka makanan yang disajikan dengan memberikan garnish menunjukan dari 6 responden yang terdapat 4 responden yang sisa makanan pokok tidak bersisa (sisa makanan $\leq 25 \%$ ) dan 2 responden 
makanannya bersisa (sisa makanan >25\%), untuk lauk hewani terdapat 5 responden yang makanannya tidak bersisa (sisa makanan $\leq 25 \%$ ) dan 1 responden makanannya bersisa (sisa makanan >25\%), untuk lauk nabati terdapat 5 responden yang makanannya tidak bersisa ( makanannya bersisa (sisa makanan $>25 \%$ ), untuk sayur terdapat 6 responden yang makanannya tidak bersisa (sisa makanan $\leq 25 \%$ ), dan untuk buah terdapat 6 responden yang buahnya tidak bersisa (sisa makanan $\leq 25 \%$ ). Sedangkan makanan yang disajikan tanpa garnih menunjukkan bahwa dari 6 responden yang terdapat 1 responden yang sisa makanan pokok tidak bersisa (sisa makanan $\leq 25 \%$ ) dan 5 responden makanannya bersisa (sisa makanan >25\%), untuk lauk hewani terdapat 2 responden yang makanannya tidak bersisa (sisa makanan $\leq 25 \%$ ) dan 4 responden makanannya bersisa (sisa makanan >25\%), untuk lauk nabati terdapat 4 responden yang makanannya tidak bersisa (sisa makanan $\leq 25 \%$ ) dan 2 responden makanannya bersisa ( isa makanan $>25 \%$ ), untuk sayur terdapat 0 responden yang makanannya tidak bersisa (sisa makanan $\leq 25 \%$ ), dan untuk buah terdapat 6 responden yang buahnya tidak bersisa (sisa makanan $\leq 25 \%) \quad$ (Tabel 7).

Tabel 7. Distribusi Sisa Makanan Pasien Ruang Edelweis (Disajikan dengan diberi Garnis) berdasarkan kategori bersisa dan tidak bersisa

\begin{tabular}{|c|c|c|c|c|c|c|c|c|c|c|c|}
\hline \multirow[t]{2}{*}{ Cara Penyajian } & \multirow{2}{*}{$\begin{array}{c}\text { Sisa } \\
\text { Makanan }\end{array}$} & \multicolumn{2}{|c|}{$\begin{array}{c}\text { Makanan } \\
\text { Pokok } \\
\end{array}$} & \multicolumn{2}{|c|}{$\begin{array}{c}\text { Lauk } \\
\text { Hewani }\end{array}$} & \multicolumn{2}{|c|}{$\begin{array}{c}\text { Lauk } \\
\text { Nabati } \\
\end{array}$} & \multicolumn{2}{|c|}{ Sayur } & \multicolumn{2}{|c|}{ Buah } \\
\hline & & $\mathrm{n}$ & $\%$ & $\mathrm{n}$ & $\%$ & $\mathrm{n}$ & $\%$ & $\mathrm{n}$ & $\%$ & $\mathrm{n}$ & $\%$ \\
\hline \multirow{2}{*}{$\begin{array}{c}\text { Diberi garnish } \\
\text { (Ruang Edelweis) }\end{array}$} & Tidak bersisa & 4 & 66,66 & 5 & 83,33 & 5 & 83,33 & 6 & 100,0 & 6 & 100,0 \\
\hline & Bersisa & 2 & 33,33 & 1 & 16,66 & 1 & 16,66 & 0 & 0 & 0 & 0 \\
\hline \multirow{2}{*}{$\begin{array}{c}\text { Tanpa Garnish } \\
\text { (Ruang Anggrek) }\end{array}$} & Tidak bersisa & 1 & 16,66 & 2 & 33,33 & 4 & 66,66 & 0 & 0 & 6 & 100 \\
\hline & Bersisa & 5 & 83,33 & 4 & 66,66 & 2 & 33,33 & 6 & 100,0 & 0 & 0 \\
\hline Total & & 6 & 100 & 6 & 100 & 6 & 100 & 6 & 100 & 6 & 100 \\
\hline
\end{tabular}

(Sumber : Data Primer, 2020)

Penilaian responden terkait penampilan makanan menunjukan pada tabel berikut:

Tabel 9. Penilaian Responden Terhadap Penampilan Makanan Yang Di Sajikan dengan diberi garnis dan tidak diberi garnis

\begin{tabular}{lcccccc}
\hline \multirow{2}{*}{$\begin{array}{c}\text { Penampilan } \\
\text { Makanan }\end{array}$} & \multicolumn{4}{c}{ Mesponden } & \multirow{2}{*}{ Menarik } & \multicolumn{2}{c}{ Tidak } & Jumlah \\
\cline { 2 - 6 } & Menarik & & \\
\cline { 2 - 6 } & n & n & $\%$ & n & $\%$ \\
\hline $\begin{array}{l}\text { Diberi } \\
\text { Garnis }\end{array}$ & 6 & 100 & 0 & 0 & 6 & 100 \\
\hline $\begin{array}{l}\text { Tidak diberi } \\
\text { garnis }\end{array}$ & 1 & 17 & 5 & 83 & 6 & 100 \\
\hline Total & 7 & 58,3 & 5 & 41,7 & 12 & 100 \\
\hline
\end{tabular}

(Sumber : Data Primer, 2020)

Penampilan makanan yang disajikan dengan diberi garnish lebih menarik menurut pasien dibandingkan dengan makanan yang disajikan tanpa diberi garnis (Tabel 9).

\section{PEMBAHASAN}

1. Sisa Makanan

Berdasarkan hasil analisis data yang dilakukan dengan menggunakan metode Comstock atau dengan melihat sisa 
makanan

pasien $2 \times 24 \quad$ jam

(Lumbantoruan, 2012) , diperoleh hasil bahwa pemberian garnish pada makanan pasien lebih mengurangi sisa makanan pasien dibandingkan dengan penyajian tanpa diberi garnis. Untuk porsi makanan pokok sebesar 300 gram, lauk hewani 200 gram, lauk nabati 220 gram, sayur 300 gram dan buah menyesuaikan dengan buah pada menu.

a. Sisa Makanan Disajikan Diberi Garnish

Hasil berdasarkan analisis sisa makanan, terdapat 6 responden yang bersedia menjadi sampel penelitian diruang rawat inap Edelweis. Dari 6 responden terdapat 4 responden yang sisa makanannya pokok $\leq 25 \%$ (dihabiskan makan $3 / 4$ porsi) dan 2 responden sisa makanan pokoknya $>25 \%$ (dihabiskan makan $\leq 1 / 2$ porsi). Untuk jenis lauk hewani maupun nabati dari 6 responden ada 5 responden yang sisa makanannya $\leq 25 \%$ (dihabiskan makan $3 / 4$ porsi) dan satu responden sisa makanannya $>25 \%$ (dihabiskan makan $\leq 1 / 2$ porsi. Sedangkan untuk sayuran dan buah semua responden dihabiskan makanan $3 / 4$ porsi (sisa makananya $\leq 25 \%$ ). Tidak ada pasien yang sisa makanannya $>75 \%$ baik makanan pokok, lauk hewani, nabati, sayuran maupun buah. Makanan yang disajikan dengan garnis sebagian besar dihabiskan makan $>3 / 4$ porsi.
Hal. $74-82$

b. Sisa Makanan Disajikan Tanpa Diberi Garnish

Ruang Rawat Inap VIP Anggrek merupakan makanan yang disajikan tidak diberi garnis terdapat bahwa ada 6 responden yang bersedia menjadi sampel penelitian diruang rawat inap anggrek. Dari 6 responden terdapat 1 responden yang sisa makanan pokoknya $\leq 25 \%$ (dihabiskan makan $3 / 4$ porsi) dan 5 responden sisa makanan pokoknya $>25 \%$ (dihabiskan makan $\leq 1 / 2$ porsi). Untuk jenis lauk hewani sebanyak 2 responden yang sisa makanannya $\leq 25 \%$ (dihabiskan makan $3 / 4$ porsi) dan 4 responden yang sisa makanannya >25\% (dihabiskan makan $3 / 4$ porsi), untuk jenis lauk nabati sebanyak 4 responden yang sisa makanannya $\leq 25 \%$ (dihabiskan makan $3 / 4$ porsi) dan 2 responden sisa makanannya $>25 \%$ (dihabiskan makan $\leq 1 / 2$ porsi), untuk jenis sayur terdapat 0 responden yang sisa makanannya $\leq 25 \%$ dan makanan yang tersisa $>25 \%$ atau $\leq 1 / 2$ porsi dihabiskan terdapat 5 responden untuk buah 6 responden sisa buah $0 \%$.

Hasil penelitian ini sejalan dengan penelitian yang dilakukan oleh Laksmi Karunia Tanuwijaya bahwa pasien sering mengeluhkan kualitas dan kuantitas makanan yang disajikan, yang ditinjau dari kesegaran dan kualitas bahan makanan, pengolahan dan penyajian makanan yang tidak 
menarik, bumbu yang kurang tajam, sedikitnya jumlah sayuran, makanan penutup dan makanan pendamping serta suhu makanan yang dingin saat diterima pasien.

2. Faktor Yang Mempengaruhi Sisa Makanan

Faktor yang mempengaruhi sisa makanan meliputi porsi makanan yang kecil dan ketiadaan makanan serta minuman diantara waktu makan. Adapun faktor internal lain menurut Hagnyonowati, 2015 yang mempengaruhi sisa makanan pasien di rumah sakit meliputi nafsu makan, kebiasaan makan, rasa bosan dan adanya makanan tambahan dari luar (Puruhita et al., 2014). Pada umumnya bagi pasien dalam keadaan sedih, merasa takut karena menderita suatu penyakit, ketidak bebasan gerak karena adanya penyakit tertentu sering menimbulkan rasa putus asa, sehingga pasien kehilangan nafsu makan, sedangkan untuk faktor eksternal meliputi cita rasa makanan, penampilan (Andani, 2013), cara penyajian, waktu penyajian dan sikap petugas (Mumu, Kandau, \& Doda, 2013). Masalah penyajian makanan kepada orang sakit lebih kompleks dari pada penyajian makanan untuk orang sehat. Hal ini disebabkan terutama oleh nafsu makan dan kondisi mental pasien berubah akibat penyakit yang diderita, penurunan aktifitas fisik dan reaksi obat-
Hal. $74-82$

obatan dan terapi diet yang harus dijalani pasien.

Sisa makanan pasien ditemukan tinggi ketika rumah sakit tidak memberikan pilihan makanan kepada pasien, diantaranya pilihan jenis sayuran, serta porsi. Menu yang tidak dideskripsikan dengan baik serta ketidakmampuan pasien untuk melihat sendiri dan memilih menu serta porsi makanan juga berkontribusi menyebabkan sisa makanan pasien (Sibagariang, 2018).

3. Wawancara Terhadap Responden

Berdasarkan hasil wawancara terhadap salah satu responden di Rumah Sakit ruang anggrek (tanpa diberi garnis) nafsu makan terkait kondisi pasien yang mengalami kesulitan bergerak, rasa tidak enak badan, rasa pahit yang dialami responden. Akan tetapi tidak memungkinkan kebutuhan zat gizi harian pasien tidak tecukupi dikarenakan pasien mengkonsumsi makanan dari luar rumah sakit. Sedangkan, wawancara terhadap salah satu responden di Rumah Sakit ruang edelweis nafsu makan terkait pemberian garnish dan menu pilihan pada makanan pasien ternyata dapat meningkatkan nafsu makan pasien dikarenakan pasien tertarik dengan penampilan makanan dan menu yang dihidangkan sesuai dengan menu yang diharapkan pasien.

4. Pendapat Pasien Terhadap Penampilan Makanan 
Pendapat dari responden tentang penampilan makanan yang disajikan oleh pihak rumah sakit untuk makanan yang disajikan dengan diberi garnis sebanyak 6 responden yang mengatakan penampilan makanan tersebut menarik, sedangkan untuk makanan yang disajikan tanpa diberi garnis sebanyak 1 responden mengatakan penampilan makanan tersebut menarik dan 5 responden mengatakan makanan tersebut tidak menarik.

\section{KESIMPULAN DAN SARAN}

Berdasarkan penelitian di RSUD Undata

Palu Provinsi Sulawesi Tengah disimpulkan bahwa terdapat 6 responden untuk makanan yang diberi garnish, dari 6 responden tersebut untuk semua jenis makanannya tidak bersisa. Sedangkan, 6 responden untuk makanan yang tidak diberi garnish, dari 6 responden tersebut hanya 1 responden yang semua jenis makanannya tidak bersisa dan 5 responden lagi makanannya bersisa (makanan pokok, lauk hewani, lauk nabati, sayur). Dan untuk pendapat dari responden tentang penampilan makanan yang disajikan oleh pihak rumah sakit untuk makanan yang disajikan dengan diberi garnis sebanyak 6 responden yang mengatakan penampilan makanan tersebut menarik, sedangkan untuk makanan yang disajikan tanpa diberi garnis sebanyak 1 responden mengatakan penampilan makanan tersebut menarik dan 5 responden mengatakan makanan tersebut tidak menarik
Saran dari penelitian ini adalah bagi Ahli Gizi diharapkan agar lebih sering memberi edukasi kepada pasien tentang tujuan dan manfaat pemberian makanan di rumah sakit, dimana dengan termakan habis makanan akan mempercepat proses penyembuhan dan memperpendek hari rawat serta mengurangi biaya perawatan.

\section{UCAPAN TERIMA KASIH}

Ucapan terima kasih diberikan kepada 1) Direktur Poltekkes Kemenkes Palu, 2) Direktur RSUD Undata Palu Provinsi Sulawesi Tengah, 3) Kepala Instalasi Gizi RSUD Undata Palu Provinsi Sulawesi Tengah

\section{DAFTAR PUSTAKA}

1. Andani, A. (2013). Faktor-Faktor yang Mempengaruhi Terjadinya Sisa Makanan pada Pasien Rawat Inap di Ruang Penyakit Dalam RSUD Cut Nyak Dhien Meulaboh.

2. Gobel, S. Y., \& Budiningsari, R. D. (2011). Menu Pilihan Diit Nasi yang di Sajikan Berpengaruh Terhadap Tingkat Kepuasan pasien VIP di Rumah Sakit Umum Daerah Provinsi Sulawesi Tenggara. JUrnal Gizi Klinik Indonesia, 7(3).

3. Habiba, R. A., \& Adriani, M. (2017). Hubungan Depresi, Asupan, dan Penampilan Makanan dengan Sisa Makan Pagi Pasien Rawat Inap (Studi di Rumah Sakit Islam Jemursari. Amerta Nutrition, 1(3).

4. L, P. W. N., K, T. A., \& W, W. I. (2015). Analisis Sisa Makanan Pasien Rawat Inap di RSUP Sanglah Denpasar Provinsi Bali. Public Health and Preventive Medicine Archive. Public Health and Preventive Medicine Archive, 3(1), 88-95.

5. Lumbantoruan, D. B. S. (2012). 
Hubungan Penampilan Makanan dan Faktor Lainnya dengan Sisa Makanan Biasa Pasien Kelas 3 Seruni RS Puri Cinere Depok Bulan April-Mei 2012.

6. Mumu, L. J., Kandau, G. D., \& Doda, D. V. (2013). Analisis Faktor-Faktror Yang Berhubungan dengan Kepuasan Pasien di Poliklinik Penyakit Dalam RSUP Prof. Dr. R.D Kandou Manado.

7. Mustakim, Kusuma, H. S., \& Ulvie, Y. N. S. (2012). Perbedaan Sisa Makanan pada Diit Biasa Berdasarkan Pemberian Garnish di Ruang Rajawali RSUP Dr. Kariadi Semarang.

8. Puruhita, N., Hagnyonowati, Adianto, S., Murbawani, E. A., \& Ardiaria, M. (2014). Gambaran Sisa Makanan dan Mutu Makanan yang di Sediakan Instalasi Gizi Rumah Sakit Umum Pusat Dr. Kariada Semarang. Diponegoro Jurnal Of Nutrition and Health, 2(3).

9. Sibagariang, D. B. (2018). Persepsi Pasien tentang Sajian Makanan di Rumah Sakit Pusat Angkatan Udara dr. S. Hardjolukit.

10. Yulianti, I., \& Damanik, M. R. R. M. (2015). Sisa Makanan Dan Kepuasaan pada Pasien Rawat Inap Kelas III di Rumah Sakit Swasta di Gresik, Jawa Timur. 